\title{
Differential Protein Expression in White Adipose Tissue from Obesity-Prone and Obesity-Resistant Mice in Response to High Fat Diet and Anti-Obesity Herbal Medicines
}

\author{
Sang Woo Kim ${ }^{\mathrm{a}}$ Tae-Jun Park ${ }^{\mathrm{a}}$ Jae Heon Choi ${ }^{\mathrm{a}}$ Kanikkai Raja Aseer \\ Ji-Young Choi ${ }^{\mathrm{b}}$ Ye Jin Kim ${ }^{\mathrm{b}}$ Myung-Sook Choib Jong Won Yun ${ }^{\mathrm{a}}$ \\ aDepartment of Biotechnology, Daegu University, Kyungsan, Kyungbuk, ${ }^{\mathrm{b}}$ Center for Food and \\ Nutritional Genomics Research, Department of Food Science and Nutrition, Kyungpook National \\ University, Daegu, Republic of Korea
}

\section{Key Words}

Anti-obesity $\cdot$ Obesity susceptibility $\cdot$ Obesity resistance $\cdot$ Proteome $\cdot$ White adipose tissue

\begin{abstract}
Background: One of the most interesting issues in obesity research is why certain humans are obesity-prone (OP) while others are obesity-resistant (OR) upon exposure to a high-calorie diet. However, the pathways responsible for these phenotypic differences are still largely unknown. Methods: In order to discover marker molecules determining susceptibility and/ or resistance to obesity in response to high fat diet (HFD) or anti-obesity herbal medicine $(\mathrm{TH})$, we conducted comparative proteomic analysis of white adipose tissue (WAT) from OP, OR, as well as TH-treated mice. Results: OP mice fed HFD gained approximately $33 \%$ more body weight than OR mice, and TH significantly reduced body weight gain in HFD-fed mice by $30 \%$. These mice were further subjected to proteomic analysis using two-dimensional electrophoresis (2-DE) combined with matrix-assisted laser desorption/ionization-time of flight mass spectrometry (MALDI-TOF-MS). Proteomic data revealed 59 spots that were differentially regulated from a total of 1,045 matched spots, and 57 spots of these were identified as altered WAT proteins between OP and OR mice by peptide mass finger printing. Interestingly, 45 proteins were similarly regulated in OR mice in response to $\mathrm{TH}$ treatment. Of these, 10 proteins have already been recognized in the context of obesity; however, other proteins involved in obesity susceptibility or resistance were identified for the first time in the present study. Conclusion: Our results suggest that $\mathrm{TH}$ actively contributed to body weight reduction in HFD-fed obese mice by altering protein regulation in WAT, and it was also found that $\mathrm{TH}$-responsive proteins can be used as potent molecules for obesity treatment.
\end{abstract}

S. W. Kim and T.-J. Park contributed equally to this work.

Dr. Jong Won Yun, and Dr. Myung-Sook Choi,

\section{KARGER 125}

Department of Biotechnology, Daegu University, Kyungsan, Kyungbuk 712-714 (Republic of Korea); and Center for Food and Nutritional Genomics Research, Department of Food Science and Nutrition, Kyungpook National University, Daegu 702-701 (Republic of Korea); E-Mail jwyun@daegu.ac.kr, E-Mail mschoi@knu.ac.kr 


\section{Cellular Physiology Cell Physiol Biochem 2015;35:1482-1498 \\ \begin{tabular}{l|l} 
and Biochemist 10.1159/000373967 & $\begin{array}{l}\text { DO 2015 S. Karger AG, Basel } \\
\text { www.karger.com/cpb }\end{array}$ \\
\hline
\end{tabular}}

\section{Introduction}

Obesity is a multifactorial disorder that is influenced by both genetic and environmental factors, leading to physical and external complications as well as progression of various diseases such as cardiovascular risks, hypertension, dyslipidemia, endothelial dysfunction, and type 2 diabetes mellitus [1-3].

Susceptibility to weight gain can vary considerably among individuals due to external influences such as excessive energy intake and low physical activity [4-6]. However, there exist large inter-individual differences in obesity development despite exposure to similar conditions. For example, some may readily gain body weight and become obese (obesityprone, OP), whereas others may not (obesity-resistant, OR) [7]. However, the pathways responsible for these phenotypic differences are still largely unknown [8].

Nowadays, prevention and management of obesity are major public health challenges and no longer considered to be only cosmetic problems. Although weight loss and weight control drugs are common, their medical effects are far from satisfactory since many pharmaceuticals have unwanted side effects [9]. Due to concerns over currently available Western medicine treatments, some have turned to their interest to alternative medicines, including traditional Oriental medicine, for therapeutic treatment of obesity [10-12].

Recent research has demonstrated that natural products may be an excellent alternative strategy for developing safe anti-obesity drugs. Medicinal plants and their extracts have been verified as beneficial and are the oldest and most widespread form of medication to prevent diet-induced obesity [12-14]. Multiple natural products containing numerous bioactive compounds may result in synergistic activity that increases their bioavailability and action on multiple molecular targets. The anti-obesity effects of these compounds are mediated by regulation of various metabolic processes, including feeding-inhibitory actions, elevation of lipolysis, reduction of lipogenesis, and differentiation of preadipocytes [15-17]. Taeumjowi-tang (designated as " $\mathrm{TH}$ ") is a traditional Korean medicine that is widely used to treat several diseases $[18,19]$. This product consists of multiple compounds and has become the standard treatment regimen for obesity by Korean medical professionals, and its use has been expanded to all types of obesity [20,21]. In previous studies, TH and TH modified prescription have been evaluated for its inhibitory effects on obesity, suggesting that its modified prescription can clinically be useful as anti-obesity drugs and can be useful for the improvement of hyperlipidemia [22, 23]. Previous clinical results have supported the antiobesity and hypolipidemic effects of $\mathrm{TH}$, but the results of clinical studies are still insufficient [18].

To discover marker molecules that could be helpful in elucidating the mechanisms underlying obesity susceptibility, various animal tissues have been studied and their whole proteomes were analyzed in order to characterize protein functions and post-translational modifications $[24,25]$. Separation, identification, and characterization of proteins as well as their interactions with other proteins are the essential goals of proteomic analysis. Twodimensional electrophoresis (2-DE) coupled with MALDI-TOF-MS is considered a powerful tool for the separation of thousands of adipose tissue proteins [26, 27]. This approach enables comparison between normal and disease samples revealing differentially expressed proteins.

Obesity-related factors in adipose tissue proteins play major roles in the development of metabolic disorders $[26,28]$. Adipose tissue acts as an active endocrine organ, which secretes adipokines contributing to the regulation of physiological processes such as energy homeostasis, reproduction, and inflammation. Several studies based on gene profiling have focused on WAT reprogramming after weight loss [29, 30]. Although DNA array is a powerful tool for this purpose, the predictive value of mRNA expression is limited with respect to cellular physiology. Expression levels of mRNA often do not parallel protein expression levels of a particular gene [31,32]. Further, protein turnover and post-translational modifications, which are essential for cellular behavior, are not covered by the information obtained from DNA data [33]. Consequently, a broader understanding of the effects of diet on WAT requires 


\section{Cellular Physiology Cell Physiol Biochem 2015;35:1482-1498 \begin{tabular}{l|l} 
and Biochemistry & $\begin{array}{l}\text { DOI: 10.1159/000373967 } \\
\text { Published online: March 12, } 2015\end{array}$ \\
\cline { 2 - 2 }
\end{tabular} Kim et al.: Anti-Obesity Herbal Medicine Alters WAT Proteome}

independent examination of protein expression and function in conjunction with mRNA expression analyses.

In the present study, we addressed the anti-obesity effects of natural traditional herbal medicines based on their abilities to alter expression of WAT proteins in HFD-induced obese mice. To the best of our knowledge, this is the first proteomics study profiling WAT protein modulation by traditional herbal medicines in an obese animal model.

\section{Materials and Methods}

Animals and breeding conditions

Four-week-C57BL/6J male mice were purchased from Jackson Laboratory (Bar Harbor, ME, USA). All mice were provided water and standard chow ad libitum for 1 week for acclimatization before the start of any experimental procedures. The mice were then randomly divided into two groups, viz. normal diet group (ND, $n=10$ ) and HFD-fed group (60\% fat, $n=30$ ), and bred for 12 weeks. HFD-fed mice were further subdivided into three groups; OP mice showed the highest body weight gain (OP group, $n=10$ ) while OR mice showed the lowest body weight gain (OR group, $n=10$ ). Among 20 HFD-fed mice, 10 mice were randomly selected and treated with TH (TH group, $n=10$ ). Taeumjowi-tang $(\mathrm{TH})$ was purchased from I-world Pharm. Co. Ltd. (Incheon, Korea). TH is a decoction consisting of eight herbal ingredients, and the ingredients of TH are Semen Coicis (11.25g), Semen Castaneae (11.25g), Semen Raphani (7.5g), Schisandrae Fructus (3.75g), Liriopis Tuber (3.75g), Herba Ephedrae (3.75g), Radix Platycodi (3.75g), and Acori Tatarinowii Rhizoma (3.75g). Dietary compositions used in this study are presented in Table 1. Mice had free access to food and distilled water during the experimental period. Food intakes and body weights were measured daily and weekly, respectively. On the 12th week, mice were anaesthetized with diethyl ether and sacrificed after 12 $\mathrm{h}$ of fasting. Blood was taken from the inferior vena cava and then centrifuged at $1,000 \times \mathrm{g}$ for $15 \mathrm{~min}$ at $4^{\circ} \mathrm{C}$, after which plasma was isolated to characterize plasma biochemistry. After blood collection, epididymal adipose tissues were promptly removed, rinsed, weighed, frozen in liquid nitrogen, and stored at $-80^{\circ} \mathrm{C}$. This animal study was approved by the Ethics Committee for Animal Studies at Kyungpook National University, Republic of Korea.

\section{Preparation of protein samples}

WAT were excised from mice immediately following anesthetization with diethyl ether after overnight fasting. The resulting tissues were then washed with cold saline solution and pulverized under liquid nitrogen and stored at $-80^{\circ} \mathrm{C}$. Tissues were lysed in $200 \mathrm{~mL}$ of rehydration buffer solution containing $7 \mathrm{M}$ urea, 2 M thiourea, 4\% CHAPS, 20 mM DTT, 1 mM PMSF, 2\% IPG buffer (Ampholyte 3/10, Bio-Rad), and a trace of bromophenol blue. Lysed tissues were then homogenized by a homogenizer (PT 1200E, Kinematica, Luzern, Switzerland) on ice, after which extracts from homogenized WAT tissues were centrifuged at $13,000 \times \mathrm{g}$ for $20 \mathrm{~min}$. The supernatant was then stored at $-80^{\circ} \mathrm{C}$ until analysis. Protein content of whole WAT tissue was determined using RC DC ${ }^{\mathrm{TM}}$ protein assay (Bio-Rad).

Table 1. Dietary compositions of normal diet (ND), high-fat diet (HFD), and high-fat diet with Taeumjowi-tang (TH)

\begin{tabular}{llll}
\hline & ND & HFD & TH \\
\hline Composition by weight, g/kg & & & \\
Casein & 200 & 265 & 265 \\
Corn starch & 397.486 & 0 & 0 \\
Sucrose & 100 & 90 & 60 \\
Maltodextrin & 132 & 160 & 160 \\
Cellulose & 50 & 65.6 & 65.6 \\
Soybean oil & 70 & 30 & 30 \\
Lard & 0 & 310 & 310 \\
Mineral mix & 35 & 48 & 48 \\
Calcium phosphate, dibasic & 0 & 3.4 & 3.4 \\
Vitamin mix & 10 & 21 & 21 \\
TBHQ antioxidant & 0.014 & 0 & 0 \\
L-cystine & 3 & 4 & 4 \\
Choline bitartrate & 2.5 & 3 & 3 \\
Taeumjowi-tang & & & 30 \\
Total (kcal/kg) & 3,800 & 5,100 & 4,980 \\
\hline
\end{tabular}




\section{Cellular Physiology Cell Physiol Biochem 2015;35:1482-1498

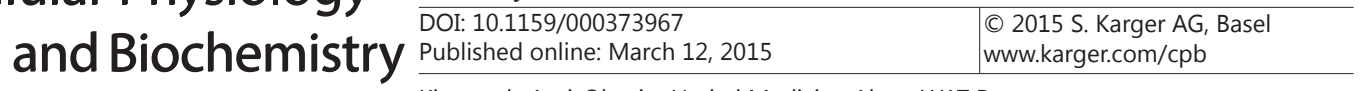 Kim et al.: Anti-Obesity Herbal Medicine Alters WAT Proteome}

Two-dimensional electrophoresis (2-DE)

2-DE was performed in duplicate using WAT protein samples from six mice per group, which consisted of ND, OP, OR, and TH mice. 2-DE experiments were conducted using the previous methods outlined by our laboratory [26, 27, 34]. Briefly, immobilized pH gradient (IPG)-isoelectric focusing (IEF) of WAT samples was performed on pH 3-10 and 18 cm IPG DryStrips (GE Healthcare, Buckinghamshire, UK) in a PROTEIN IEF cell (Bio-Rad) using the protocol recommended by the manufacturer. IPG strips were rehydrated passively for $12 \mathrm{~h}$ in strip holders with $350 \mu \mathrm{L}$ of rehydration solution, which included $7 \mathrm{M}$ urea (Bio Basic, Ontario, Canada), 2 M thiourea (Sigma, St. Louis, MO, USA), 4\% CHAPS (Bio Basic), 1 mM PMSF (Sigma), $20 \mathrm{mM}$ DTT (GE Healthcare), 2\% IPG buffer (Bio-Rad), and $150 \mu \mathrm{g}$ of WAT proteins. IEF was executed as follows: 15 min at $250 \mathrm{~V}, 3 \mathrm{~h}$ at $250-10,000 \mathrm{~V}, 6 \mathrm{~h}$ at $10,000 \mathrm{~V}$, and then held at $500 \mathrm{~V}$ until ready to run in the second dimension. After focusing, the gel strips were equilibrated in a solution containing $6 \mathrm{M}$ urea, $2 \%$ SDS (Generay Biotech, Shanghai, China), 1\% DTT, 30\% glycerol (Bio Basic), and $50 \mathrm{mM}$ Tris-HCl (pH 6.8) for $15 \mathrm{~min}$, followed by further incubation in the same solution, except for replacement of DTT with $2.5 \%$ iodoacetamide (Bio-Rad) for an additional 15 min period. Gel strips were then placed onto a $20 \times 20 \mathrm{~cm}$ $12 \%$ polyacrylamide gel for resolution in the second dimension. Fractionation was performed using the Laemmli SDS discontinuous system at a constant voltage of $15 \mathrm{~mA}$ per gel for $14 \mathrm{~h}$. For image analysis and peptide mass fingerprinting (PMF), a total of 48 gels, including two gels per group with separated proteins, were visualized by silver staining. Silver staining was performed as follows: gels were fixed over a period of $2 \mathrm{~h}$ in $50 \%$ ethanol and 5\% acetic acid, followed by $10 \mathrm{~min}$ in $30 \%$ ethanol and washing in water for $5 \mathrm{~min}$ three times. Gels were sensitized for $10-15 \mathrm{~min}$ in $0.02 \%$ sodium thiosulfate (Sigma), followed by washing in water for $0.5 \mathrm{~min}$ three times and incubation for $1 \mathrm{~h}$ in $0.3 \%$ silver nitrate (Kojima Chemicals, Sayama, Japan). After washing in water two times for $1 \mathrm{~min}$, proteins were visualized with developing solution containing $3 \%$ sodium carbonate, $0.02 \%$ sodium thiosulfate, and $0.05 \%$ formalin and then stopped using $6 \%$ acetic acid.

\section{Image acquisition and data analysis}

Gels were imaged on a UMAX PowerLook 1120 (Maxium Technologies, Akron, OH, USA), and modified ImageMaster 2-D software V4.95 (GE Healthcare) was used for comparison of images. A reference gel was selected from gels of the normal group, and detected spots from other gels were matched with those in the reference gel. Relative optical density and relative volume were calculated in order to correct differences in gel staining. Each spot intensity volume was processed by background subtraction and total spot volume normalization, and the resulting spot volume percentage was used for comparison.

\section{Protein identification}

For protein identification by PMF, protein spots were excised, digested with trypsin (Promega, Madison, WI, USA), mixed with CHCA in 50\% ACN/0.1\% TFA, and subjected to MALDI-TOF analysis (Microflex LRF 20, Bruker Daltonics). Spectra were collected from 300 shots per spectrum over an m/z range of 600-3000 and calibrated by two-point internal calibration using trypsin auto-digestion peaks ( $\mathrm{m} / \mathrm{z} 842.5099,2211.1046$ ). Peak list was generated using Flex Analysis (ver 3.0). The threshold used for selecting peaks was as follows: 500 for minimum resolution of monoisotopic mass, 5.0 for S/N. Peptide masses were matched with the theoretical peptides of all proteins in the NCBI database using MASCOT developed by Matrixscience (http:// www.matrixscience.com). The following parameters were used for the database search: trypsin as the cleaving enzyme, a maximum of one missed cleavage, iodoacetamide (Cys) as a complete modification, oxidation (Met) as a partial modification, monoisotopic masses, and a mass tolerance of \pm 0.1 Da. Protein score is $-10 * \log (p)$, where $p$ is the probability that the observed match is a random event, and greater than 61 is significant $(p<0.05)$.

\section{Immunoblot analysis}

Tissue lysates were prepared with RIPA buffer (Sigma), homogenized, and centrifuged at $12,000 \times g$ for $20 \mathrm{~min}$. The extract was diluted in sample buffer (50 mM Tris of pH 6.8, 2\% SDS, 10\% glycerol, $0.1 \%$ bromophenol blue, and $5 \% \beta$-mercaptoethanol) and heated for $5 \mathrm{~min}$ in a boiling bath. Samples were then subjected to SDS-polyacrylamide gel electrophoresis and transferred to Poly-Screen membranes (NEN, Boston, MA, USA). Membranes were subsequently blocked with 5\% nonfat dry milk in TBS (10 mM Tris$\mathrm{HCl}, 150 \mathrm{mM} \mathrm{NaCl}, \mathrm{pH} 7.5$ ) containing 0.1\% Tween-20 (TBS-T). After washing with TBS-T, membranes were 


\section{Cellular Physiology Cell Physiol Biochem 2015;35:1482-1498 \begin{tabular}{ll|l} 
and Biochemistry & $\begin{array}{l}\text { DOI: 10.1159/000373967 } \\
\text { Published online: March 12, } 2015\end{array}$ & $\begin{array}{l}\text { ( ) 2015 S. Karger AG, Basel } \\
\text { www.karger.com/cpb }\end{array}$ \\
\hline
\end{tabular} Kim et al.: Anti-Obesity Herbal Medicine Alters WAT Proteome}

Table 2. List of RT-PCR primers. ${ }^{a} \mathrm{~F}$, sequence from sense strands; ${ }^{b} \mathrm{R}$, sequence from anti-sense strands

\begin{tabular}{lll}
\hline Genes & & Primer sequence $\left(5^{\prime}-3^{\prime}\right)$ \\
\hline Anxa1 & $\mathrm{F}^{a}$ & ACCAACCCATTGCTTCCAT \\
& $\mathrm{R}^{b}$ & AAGCCAGCCTCAATGGTCTC \\
Fabp4 & $\mathrm{F}$ & GACCAGCAGGAGCTTTCCTC \\
& $\mathrm{R}$ & TGGCACACTTCACGATGGTT \\
Idh1 & $\mathrm{F}$ & ATCGACTTGGGGACCACCTA \\
Internal control & $\mathrm{R}$ & CAATCAGACGCTCCCCTTCA \\
Gusb & $\mathrm{F}$ & \\
& $\mathrm{R}$ & AGAACAACAGCCTTCCACCTT \\
& & \\
\end{tabular}

incubated for $2 \mathrm{~h}$ with a 1:1000 dilution of primary polyclonal mice antibody (anti-CEBP $\alpha$, anti-CEBP $\beta$, antiPPAR $\gamma$, anti-LPL, anti-FABP4, and anti- $\beta$-actin; Santa Cruz Biotechnology, Santa Cruz, CA, USA), followed by HRP-conjugated anti-rabbit IgG, anti-goat IgG, and anti-mouse IgG secondary antibody (1:1000; Santa Cruz Biotechnology) for $1 \mathrm{~h}$ and development using enhanced chemiluminescence (iNtRON Biotechnology, Seoul, Korea). Western blot was analyzed by scanning with UMAX PowerLook 1120 (Maxium Technologies) and digitalization using image analysis software (KODAK 1D, Eastman Kodak, Rochester, NY, USA).

\section{Network analysis}

Associations of differentially expressed genes with broadly defined molecular networks were carried out using IPA (Ingenuity Pathway Analysis, http://www.ingenuity.com) tools. Molecular networks were predicted based on the direct and indirect relationships between differentially expressed molecules and members of the networks in the IPA database. When using IPA, we analyzed up-regulated and downregulated proteins for each group as separate groups. Only values that were significant at $p<0.01$ showing FDR correction and at least a 2 -fold change in protein levels were included in the analysis.

\section{Real-time RT-PCR}

Transcription levels of genes were quantitatively determined by real-time RT-PCR (Stratagene Mx 3000p QPCR System, Santa Clara, CA, USA). Total RNA was isolated from WAT tissues using an easy-spin TM (DNA-free) Total RNA Extraction kit, and reverse-transcription was carried out using a Maxime RT Premix kit (iNtRON Biotechnology). We employed FastStart Universal SYBR Green Master (Roche Diagnostics, Indianapolis, IN, USA) for real-time RT-PCR. Transcription levels of each gene (Anxa1, Fabp4, and Idh1) were normalized to Gusb transcription levels. Oligonucleotide sequences are shown in Table 2.

\section{Statistical analysis}

All experimental results were compared by One-way Analysis of Variance (ANOVA) using the Statistical Package of Social Science (SPSS, version $14.0 \mathrm{~K}$ ) program; data are expressed as the mean \pm SEM. A protected least-significant difference (LSD) test, which is a method for multiple comparison consisting of single-step procedures in One-way ANOVA, was used to demonstrate significant differences between means $(p<0.05)$.

\section{Results}

Effects of TH treatment in HFD-fed obese mice

Changes in body weight among individuals during the experimental period are shown in Fig. 1A. Body weights of mice were the same among all groups at the beginning of this study. However, after inducing obesity with HFD for 4 weeks, OP mice were heavier $(p<0.01)$ than normal controls and OR mice at all subsequent time points (data not shown). Accordingly, body weight gain in OP mice was approximately 33\% higher than that in OR mice (Fig. 1A). No significant difference was observed in energy intake (total food intake) per total body weight between OP, OR, and TH mice (Fig. 1B). Moreover, total WAT weight in OP mice was higher $(p<0.01)$ than those in normal, OR, and TH mice (Fig. 1C). After TH treatment for 12 weeks, total WAT per body weight was significantly reduced by up to $15 \%(p<0.01)$ compared to the 


\section{Cellular Physiology Cell Physiol Biochem 2015;35:1482-1498 \begin{tabular}{c|c|c|}
\hline DOI: 10.1159/000373967 & O 2015 S. Karger AG, Bas
\end{tabular} \\ Kim et anti- Antity}

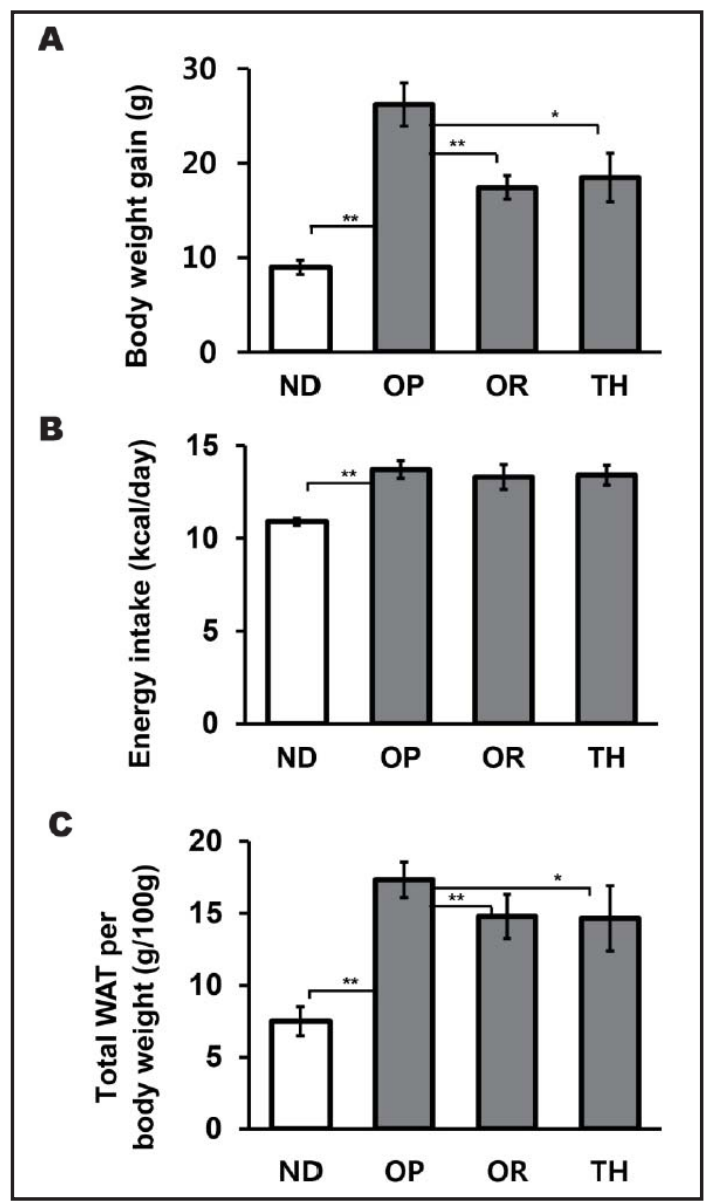

Fig. 1. (A) Average body weight gain, (B) energy intake, (C) average weight of WAT per body weight in mice fed normal diet (ND), HFD-fed obesity-prone mice (OP), HFD-fed obesity-resistant mice (OR), and HFD-fed obese mice treated with the herbal medicine Taeumjowi-tang (TH). Statistical significance was determined by One-way ANOVA test, where $p$ values are $^{*} p<0.05$ and ${ }^{* *} p<0.01$ for significance. Error bars represent means \pm S.E.M $(n=6)$.

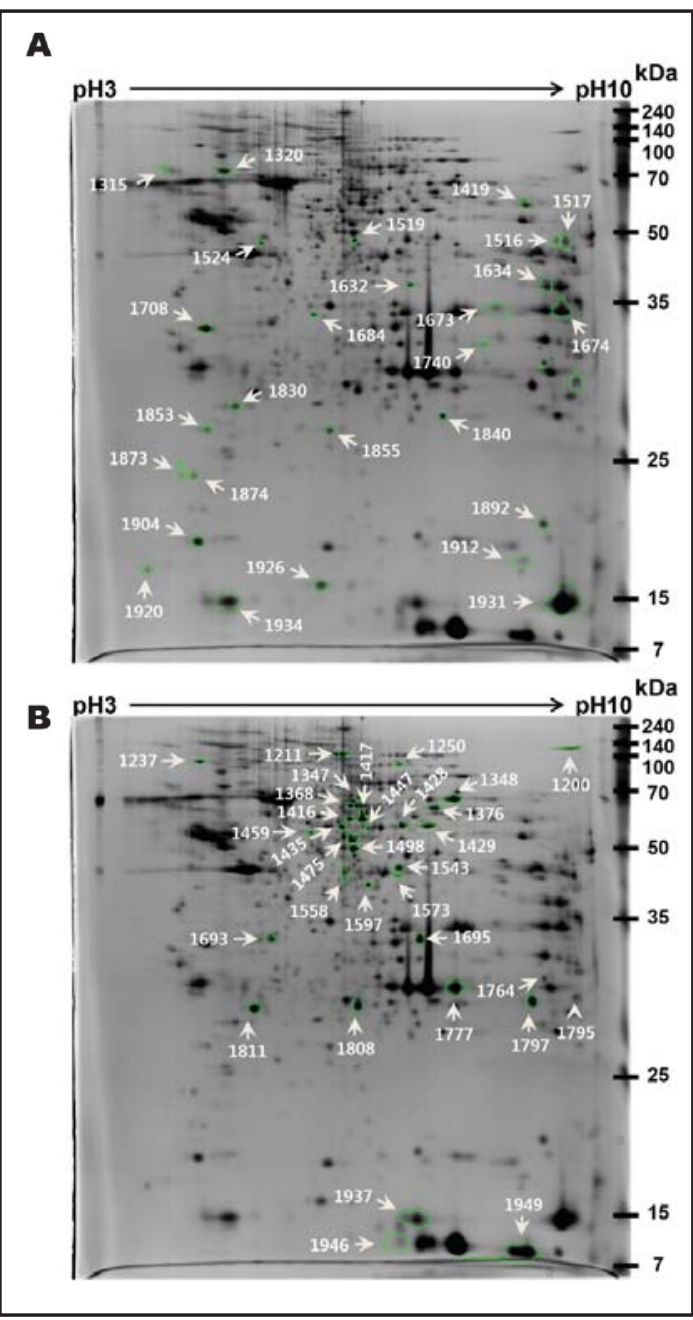

Fig. 2. Representative silver-stained 2-DE gel images of mice WAT proteome. (A) Up-regulated and (B) down-regulated proteins in OP mice compared to ND-fed mice. Differentially regulated proteins and proteins of interest are marked with circles and arrows. The numbers in gels are listed in Table 3.

OP group. Collectively, these results suggest that TH inhibited fat accumulation in HFD-fed obese mice, prompting us to perform further proteomic studies.

\section{Proteomic analysis of WAT}

For identification of differentially expressed proteins among the four groups (ND, OP, OR, and TH group), WAT protein samples were separated by 2-DE (Fig. 2), protein spots were identified by MALDI-TOF-MS (Table 3), and database searches were performed with high confidence based on high score and sequence coverage. For the results, a total of 1,045 individual matched spots ranging in mass from 6 to $240 \mathrm{kDa}$ between $\mathrm{pH} 3-10$ were detected, and obtained WAT protein maps represented patterns that were similar to our previous results $[26-28,34]$. Fifty-nine spots were identified with statistically different intensities between the ND and OP groups. These differentially altered spots dramatically changed in response to $\mathrm{TH}$, suggesting that $\mathrm{TH}$ played a pivotal role in obesity prevention in HFD-fed obese mice. 


\section{Cellular Physiology Cell Physiol Biochem 2015;35:1482-1498 \begin{tabular}{l|l|l}
\hline DOI: 10.1159/000373967 & O 2015 S. Karger AG, Basel
\end{tabular} and Biochemistry Published online: March 12, 2015 www.karger.com/cpb

Table 3. List of identified proteins showing differential expression ( $2 \geq$ fold change) in white adipose tissue (WAT) between mice fed normal diet or high fat diet (OP, OR, and TH groups). ${ }^{\text {a }}$ NCBInr/SWISS database accession number. ${ }^{\mathrm{b}}$ The nominal mass is the integer mass of the most abundant naturally occurring stable isotope of an element. ${ }^{\mathrm{c}}$ MASCOT probability-based molecular-weight search score calculated for PMF. Protein score is $-10 \times \log (P)$, where $P$ is the probability that the observed match is a random event; it is based on the NCBInr database using the MASCOT searching program as MS/MS data and protein scores $>61$ are significant $(P<0.05) .{ }^{d}$ ND means not detected. Spot Id is same numbers in gel image of Fig. 2

\begin{tabular}{|c|c|c|c|c|c|}
\hline Spot ID & Description & Acc. No. ${ }^{a}$ & $\begin{array}{l}\text { Nomina } \\
1 \text { mass } \\
\left(M_{r}\right)^{b}\end{array}$ & $\begin{array}{c}\text { Calculated } \\
\text { PI }\end{array}$ & Score $^{c}$ \\
\hline 1200 & Alanyl-tRNA editing protein Aarsd1 & AASD1_MOUSE & 45228 & 6.00 & 47 \\
\hline 1211 & Pyruvate carboxylase, mitochondrial isoform 2 & gi|251823978 & 129618 & 6.25 & 154 \\
\hline 1237 & Heat shock protein 90 , beta (Grp94), member 1 & gi|14714615 & 92432 & 4.74 & 97 \\
\hline 1250 & Elongation factor 2 & gi|33859482 & 95253 & 6.41 & 65 \\
\hline 1315 & PHD and RING finger domain-containing protein 1 & PHRF1_MOUSE & 185622 & 8.87 & 30 \\
\hline 1320 & $78 \mathrm{kDa}$ glucose-regulated protein precursor & gi|254540166 & 72378 & 5.01 & 207 \\
\hline 1347 & PREDICTED: WD repeat-containing protein 1 isoform $X 1$ & gi|568934035 & 58889 & 6.52 & 98 \\
\hline 1348 & Transketolase & gi|11066098 & 60545 & 6.54 & 73 \\
\hline 1368 & EH domain-containing protein 2 & gi|55742711 & 61136 & 6.08 & 142 \\
\hline 1376 & Me1 protein & gi|13096987 & 63799 & 6.87 & 133 \\
\hline 1416 & Bicaudal D-related protein 2 & BICR2_MOUSE & 57607 & 4.93 & 39 \\
\hline 1417 & Triacylglycerol hydrolase & gi|14269427 & 61848 & 6.30 & 156 \\
\hline 1419 & PREDICTED: zinc finger protein 787 isoform $\mathrm{X} 1$ & gi|568946454 & 49505 & 9.15 & 69 \\
\hline 1428 & Aldehyde dehydrogenase family 6 , subfamily A1 & gi|23271115 & 57924 & 8.25 & 102 \\
\hline 1429 & Katanin p60 ATPase-containing subunit A-like 1 & KATL1_MOUSE & 55472 & 6.67 & 52 \\
\hline 1435 & NDd & ND & ND & ND & ND \\
\hline 1447 & Endonuclease 8 -like 2 & NEIL2_MOUSE & 37210 & 8.76 & 36 \\
\hline 1459 & mRNA turnover protein 4 homolog & MRT4_MOUSE & 27642 & 8.63 & 34 \\
\hline 1475 & Aldehyde dehydrogenase, mitochondrial precursor & gi|6753036 & 56502 & 7.53 & 103 \\
\hline 1498 & Enolase $1 \mathrm{~B}$, retrotransposed & gi|70794816 & 47111 & 6.37 & 89 \\
\hline 1516 & Serine (or cysteine) peptidase inhibitor, clade $\mathrm{H}$, member 1 , isoform CRA_a & gi|148684430 & 44954 & 9.01 & 87 \\
\hline 1517 & Serine (or cysteine) peptidase inhibitor, clade $\mathrm{H}$, member 1 , isoform CRA_a & gi|148684430 & 44954 & 9.01 & 159 \\
\hline 1519 & Exosome complex component RRP40 & EXOS3_MOUSE & 30041 & 8.35 & 55 \\
\hline 1524 & PACRG-like protein & PACRL_MOUSE & 27615 & 9.92 & 58 \\
\hline 1543 & NADP-dependent isocitrate dehydrogenase & gi|3641400 & 46630 & 6.48 & 79 \\
\hline 1558 & Dual specificity phosphatase 28 & DUS28_MOUSE & 17779 & 7.66 & 48 \\
\hline 1573 & Cell division control protein 6 homolog & CDC6_MOUSE & 63658 & 9.43 & 50 \\
\hline 1597 & Conserved oligomeric Golgi complex subunit 4 & COG4_MOUSE & 89574 & 5.06 & 40 \\
\hline 1632 & Aldo-keto reductase family 1 , member $\mathrm{A} 4$ & gi|148698648 & 30208 & 6.35 & 110 \\
\hline 1634 & Aldolase A & gi|7548322 & 39526 & 8.55 & 137 \\
\hline 1673 & Centrosomal protein of $85 \mathrm{kDa}$ & CEP85_MOUSE & 86085 & 5.86 & 46 \\
\hline 1674 & Glyceraldehyde-3-phosphate dehydrogenase & gi|55153885 & 35751 & 7.59 & 126 \\
\hline 1684 & DNA-directed RNA polymerases I and III subunit RPAC1 & RPAC1_MOUSE & 39310 & 5.09 & 44 \\
\hline 1693 & Transcription elongation factor A protein 2 & TCEA2_MOUSE & 34325 & 9.32 & 32 \\
\hline 1695 & Monoglyceride lipase isoform a & gi|261878516 & 35234 & 7.21 & 103 \\
\hline 1708 & Annexin A5 & gi|6753060 & 35730 & 4.83 & 186 \\
\hline 1740 & Annexin A1 & gi $\mid 124517663$ & 38710 & 6.97 & 68 \\
\hline 1764 & Parp3 protein & gi|15928823 & 60003 & 6.53 & 38 \\
\hline 1777 & mRNA turnover protein 4 homolog & MRT4_MOUSE & 27642 & 8.63 & 46 \\
\hline 1795 & GTP:AMP phosphotransferase $\mathrm{AK} 3$, mitochondrial & gi|23956104 & 25467 & 8.87 & 68 \\
\hline 1797 & Glutathione S-transferase Mu 1 & gi|6754084 & 25953 & 7.71 & 103 \\
\hline 1808 & Unnamed protein product & gi|74191773 & 38749 & 6.22 & 115 \\
\hline 1811 & PREDICTED: serine/threonine-protein kinase 25 isoform X2 & gi|568909449 & 29514 & 5.51 & 73 \\
\hline 1830 & Major vault protein & MVP_MOUSE & 96150 & 5.43 & 38 \\
\hline 1840 & Galectin-7 & gi|31543120 & 15250 & 6.37 & 42 \\
\hline 1853 & Sdccag1 protein & gi|54887337 & 47900 & 6.21 & 53 \\
\hline 1855 & Calcium-binding mitochondrial carrier protein SCaMC-3 & SCMC3_MOUSE & 52692 & 7.19 & 46 \\
\hline 1873 & Cytochrome b5 type B precursor & gi|31542438 & 16308 & 4.79 & 70 \\
\hline 1874 & Cytochrome b5 type B precursor & gi|31542438 & 16308 & 4.79 & 103 \\
\hline 1892 & Cofilin-1 & gi|6680924 & 18548 & 8.22 & 96 \\
\hline 1904 & Cytochrome b5 & gi|13385268 & 15232 & 4.96 & 143 \\
\hline 1912 & Peroxisomal membrane protein 20 & gi|6746357 & 17004 & 7.71 & 175 \\
\hline 1920 & Adenylate kinase 8 & gi|152963553 & 55437 & 6.62 & 46 \\
\hline 1926 & Alpha-(1,3)-fucosyltransferase 11 & FUT11_MOUSE & 56068 & 5.81 & 38 \\
\hline 1931 & Fatty acid-binding protein, adipocyte & gi|14149635 & 14641 & 8.53 & 139 \\
\hline 1934 & ND & ND & ND & ND & ND \\
\hline 1937 & FYVE, RhoGEF and PH domain-containing protein 6 & FGD6_MOUSE & 156954 & 8.09 & 45 \\
\hline 1946 & Hemoglobin, beta adult $t$ chain & gi|31982300 & 15738 & 7.14 & 85 \\
\hline 1949 & Hemoglobin alpha, adult chain 2 & gi|145301549 & 15103 & 7.96 & 71 \\
\hline
\end{tabular}

Differential expression of obesity-associated proteins in WAT

Prior to comparison of differentially altered proteins between OP and OR mice, we first compared WAT protein levels among ND, OP, and OR mice. Most of the identified proteins showed significantly altered protein expression between OP and ND-fed mice in response 

Cellular Physiology Cell Physiol Biochem 2015;35:1482-1498 \begin{tabular}{l|l|l} 
DOI: 10.1159/000373967 & O 2015 S. Karger AG, Basel
\end{tabular} \begin{tabular}{l|l} 
and Biochemistry Published online: March 12, 2015 & www.karger.com/cpb
\end{tabular}

Fig. 3. Differentially regulated proteins in WAT from OP mice compared with ND/OR/TH mice. (A) Up-regulated and (B) down-regulated proteins in OP mice. Each bar shows an average volume density (\%) in 2-DE analysis. Statistical significances between ND and OP were determined by One-way ANOVA test, where $p<0.05$.

to $\mathrm{TH}$ treatment, whereas 45 proteins showed similar levels in OR mice (Fig. 3). A total of 26 proteins were up-regulated in OP mice while also maintained at low levels in ND and OR mice. Furthermore, analysis of WAT samples identified 31 proteins that were downregulated in HFD-fed OP mice but up-regulated in normal and OR mice. Until now, most of these proteins have not been shown as being differentially expressed in WAT in response to HFD. Therefore, these proteins can be considered as potential marker proteins for determination of phenotypic differences in WAT between OP and OR mice.

We also investigated differential expression of WAT proteins between $\mathrm{OP}$ and TH mice based on the above results for ND and OP mice. A total of 10 proteins showed significantly altered protein expression upon $\mathrm{TH}$ treatment between $\mathrm{OP}$ and $\mathrm{TH}$ mice. Among these, five proteins were up-regulated while five proteins were down-regulated in OP mice. Interestingly, all of these proteins showed opposite expression patterns between $\mathrm{OP}$ as well as OR and TH mice (Fig. 4), thereby confirming a role for TH in metabolic balance in adipose tissue.

\begin{tabular}{|c|c|c|}
\hline \multicolumn{3}{|l|}{$\mathbf{A}$} \\
\hline Spot ID & Identified proteins & $\begin{array}{l}\text { Expression levels } \\
\text { ND OP OR TH }\end{array}$ \\
\hline 1315 & PHD and RING finger domain-containing protein 1 & $--a_{-}$ \\
\hline 1320 & $78 \mathrm{kDa}$ glucose-regulated protein precursor & $-\square--$ \\
\hline 1419 & PREDICTED: zinc finger protein 787 isoform XI & $-\square--$ \\
\hline 1516 & $\begin{array}{l}\text { Serine (or cysteine) peptidase inhibitor, clade } \mathrm{H} \text {, member } \mathrm{l} \text {, } \\
\text { isoform CRA_a }\end{array}$ & $-\square-\boldsymbol{n}$ \\
\hline 1517 & $\begin{array}{l}\text { Serine (or cysteine) peptidase inhibitor, elade } \mathrm{H} \text {, member } \mathrm{I} \text {, } \\
\text { isoform CRA_a }\end{array}$ & $-\square=-$ \\
\hline 1519 & Exosome complex component RRP40 & 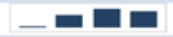 \\
\hline 1524 & PACRG-like protein & $-\square=-$ \\
\hline 1632 & Aldo-keto reductase family 1 , member A4 & $-\boldsymbol{\square} \boldsymbol{\square}$ \\
\hline 1634 & Aldolase A & $-\square=-$ \\
\hline 1673 & Centrosomal protein of $85 \mathrm{kDa}$ & $-\square=-$ \\
\hline 1674 & Glyceraldehyde-3-phosphate dehydrogenase & - $\square=$ \\
\hline 1684 & DNA-directed RNA polymerases I and III subunit RPACl & $-\square=-$ \\
\hline 1708 & Annexin A5 & $-a_{-}=$ \\
\hline 1740 & Annexin Al & $-\square=\ldots$ \\
\hline 1830 & Major vault protein & 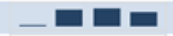 \\
\hline 1840 & Galectin-7 & $-\square=-$ \\
\hline 1853 & Sdccagl protein & $-\boldsymbol{a}_{-}$ \\
\hline 1855 & Calcium-binding mitochondrial carrier protein SCaMC-3 & $-\square--$ \\
\hline 1873 & Cytochrome b5 type B precursor & $-\square \ldots$ \\
\hline 1874 & Cytochrome b5 type B precursor & $-\boldsymbol{a}-$ \\
\hline 1892 & Cofilin-1 & $-\square=-$ \\
\hline 1904 & Cytochrome b5 & $-\square=$ \\
\hline 1912 & Peroxisomal membrane protein 20 & $-\boldsymbol{E} \boldsymbol{E}_{-}$ \\
\hline 1920 & Adenylate kinase 8 & $-=\square_{-}$ \\
\hline 1926 & Alpha-(1,3)-fucosyltransferase 11 & $-\boldsymbol{a}=$ \\
\hline 1931 & Fatty acid-binding protein, adipocyte & $-\square--$ \\
\hline \multicolumn{3}{|l|}{ B } \\
\hline Spot ID & Identified proteins & $\begin{array}{l}\text { Expression levels } \\
\text { ND OP OR TH }\end{array}$ \\
\hline 1200 & Alanyl-tRNA editing protein Aarsdı & $\mathbf{n}_{-\mathbf{E}}$ \\
\hline 1211 & Pyruvate carboxylase, mitochondrial isoform 2 & $=--$ \\
\hline 1237 & Heat shock protein 90, beta (Grp94), member I & $-n-$ \\
\hline 1250 & Elongation factor 2 & $--\square=$ \\
\hline 1347 & $\begin{array}{l}\text { PREDICTED: WD repeat-containing protein } 1 \text { isoform } \\
\text { XI }\end{array}$ & $=-\mathbf{n}$ \\
\hline 1348 & Transketolase & $\mathbf{n}_{-} \mathbf{n}$ \\
\hline 1368 & EH domain-containing protein 2 & - -- \\
\hline 1376 & Mel protein & - - \\
\hline 1416 & Bicaudal D-related protein 2 & $\mathbf{n}-\boldsymbol{n}$ \\
\hline 1417 & Triacylglycerol hydrolase & - \\
\hline 1428 & Aldchyde dehydrogenase family 6 , subfamily AI & - $-\boldsymbol{n}$ \\
\hline 1429 & Katanin p60 ATPase-containing subunit A-like I & $=-\mathbf{E}$ \\
\hline 1447 & Endonuclease 8-like 2 & $=\mathbf{n}=$ \\
\hline 1459 & mRNA turnover protein 4 homolog & $=-\mathbf{n}$ \\
\hline 1475 & Aldehyde dehydrogenase, mitochondrial precursor & - - - \\
\hline 1498 & Enolase IB, retrotransposed & 드. \\
\hline 1543 & NADP-dependent isocitrate dehydrogenase & - - $\mathbf{E}$ \\
\hline 1558 & Dual specificity phosphatase 28 & $=-\mathbf{m}$ \\
\hline 1573 & Cell division control protein 6 homolog & $--\mathbf{E}-$ \\
\hline 1597 & Conserved oligomeric Golgi complex subunit 4 & $=-\mathbf{a}$ \\
\hline 1693 & Transcription elongation factor A protein 2 & $\mathbf{n}-\mathbf{n}$ \\
\hline 1695 & Monoglyceride lipase isoform a & $\mathbf{n}-\mathbf{n}$ \\
\hline 1764 & Parp3 protein & $=-$ \\
\hline 1777 & mRNA turnover protein 4 homolog & - $=$ \\
\hline 1795 & GTP:AMP phosphotransferase AK3, mitochondrial & $--\mathbf{n}$ \\
\hline 1797 & Glutathione S-transferase Mu 1 & $--\mathbf{a}$ \\
\hline 1808 & Unnamed protein product & $=-\boldsymbol{a}$ \\
\hline 1811 & $\begin{array}{l}\text { PREDICTED: serine threoninc-protein kinase } 25 \text { isoform } \\
X_{2}\end{array}$ & $--n$ \\
\hline 1937 & FYVE, RhoGEF and PH domain-containing protein 6 & $=-\boldsymbol{n}$ \\
\hline 1946 & Hemoglobin, beta adult t chain & 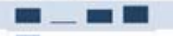 \\
\hline 1949 & Hemoglobin alpha, adult chain 2 & 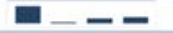 \\
\hline
\end{tabular}
KARGER 


\section{Cellular Physiology Cell Physiol Biochem 2015;35:1482-1498 \begin{tabular}{l|l|l}
\hline DOI: 10.1159/000373967 & (C) 2015 S. Karger AG, Basel
\end{tabular} \begin{tabular}{l|l} 
and Biochemistry Published online: March 12, 2015 & www.karger.com/cpb \\
\hline
\end{tabular}}

A
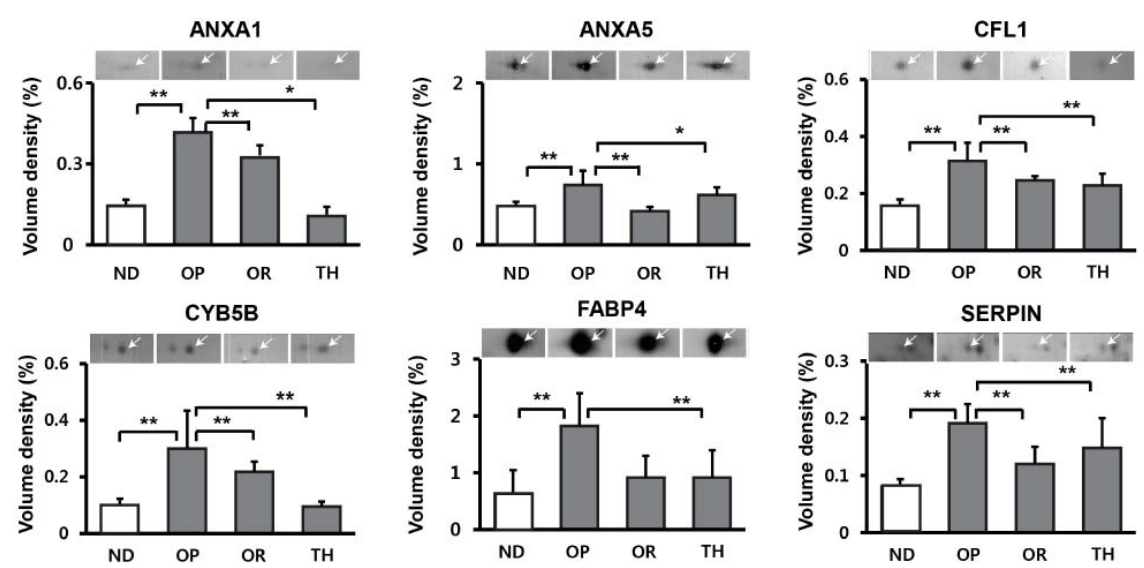

B
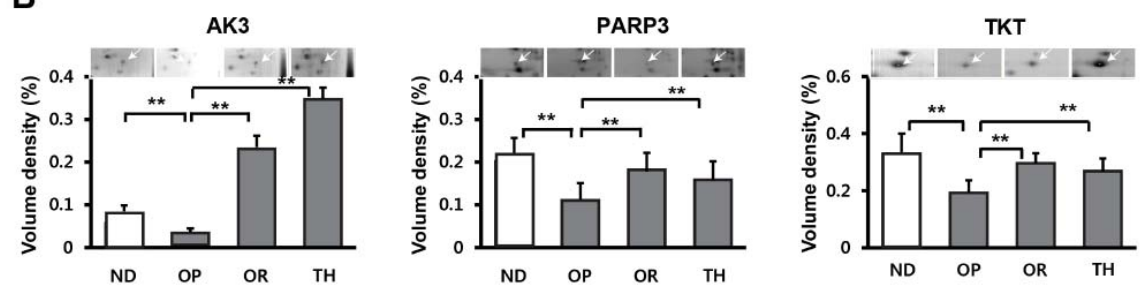

Fig. 4. Comparison of expression patterns of obesity-related proteins between OP and ND/OR/TH mice. (A) Up-regulated and (B) down-regulated proteins in OP mice. For full name of each protein, see Abbreviations. Band intensity was calculated by ImageMaster 2D software version 4.95, and relative intensity (\%) refers to the values of target proteins normalized to those of $\beta$-actin. Statistical significance was determined by Oneway ANOVA test, where $p$ values are ${ }^{*} p<0.05$ and ${ }^{* *} p<0.01$.

Fig. 5. Differentially regulated adipogenic factors in WAT as determined by immunoblot analysis. For full name of each protein, see Abbreviations. Data are representative of three independent experiments. Statistical significance was determined by One-way ANOVA test, where $p$ values were ${ }^{*} p<0.05$ and ${ }^{* *} p<0.01$.
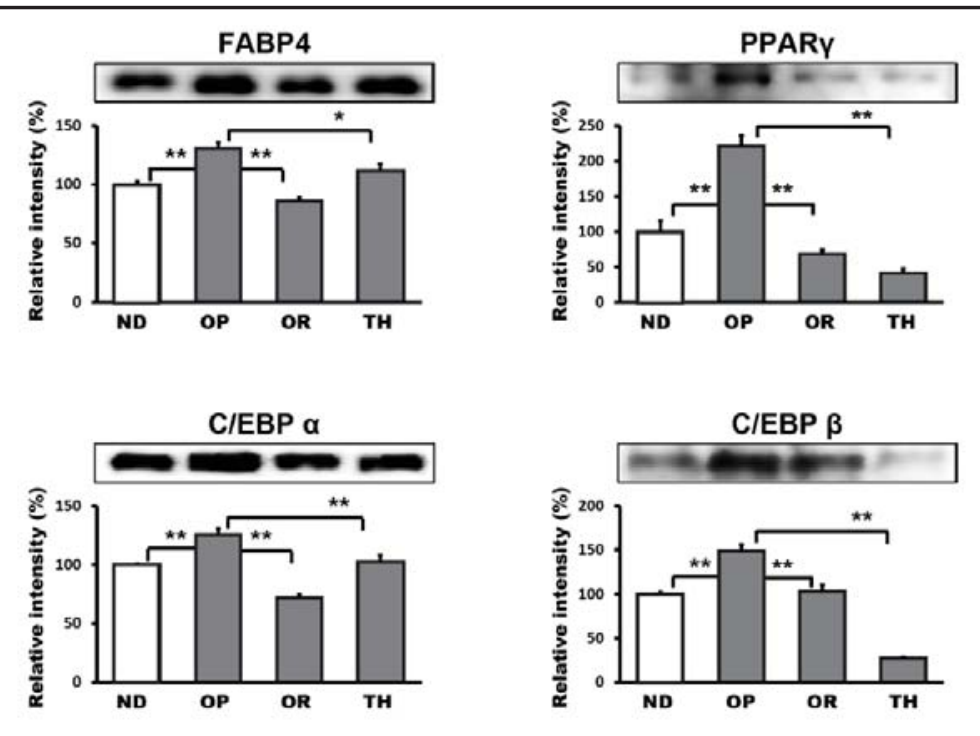

Distinct expression of adipogenic factors between OP and OR mice

We also examined differential expression patterns of adipogenic factors that could not be detected by 2-DE analysis in WAT from each group of mice. It is well known that C/EBP $\alpha$, $\mathrm{C} / \mathrm{EBP} \beta$, and PPAR $\gamma$ are master regulators of adipogenesis that induce expression of lipid metabolic proteins such as FABP4 and LPL. Immunoblot analysis was performed on five 


\section{Cellular Physiology Cell Physiol Biochem 2015;35:1482-1498 \begin{tabular}{ll|l} 
and Biochemistry & $\begin{array}{l}\text { DOb: 10.1159/000373967 } \\
\text { Published online: March 12, } 2015\end{array}$ & $\begin{array}{l}\text { ○ 2015 S. Karger AG, Basel } \\
\text { www.karger.com/cpb }\end{array}$ \\
\hline
\end{tabular}

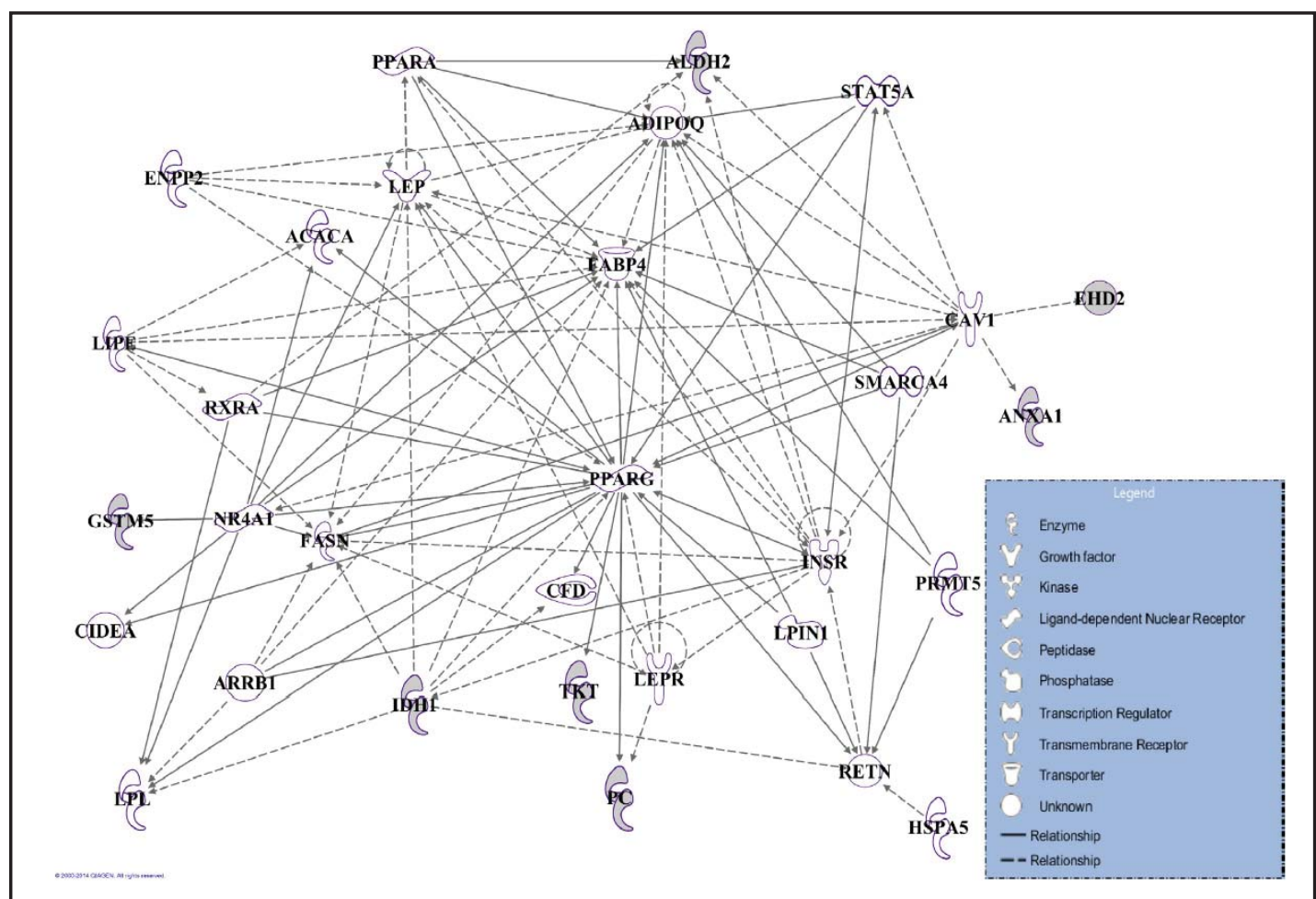

Fig. 6. Networks generated by Ingenuity Pathway Analysis using up- or down-regulated proteins in response to HFD and TH treatments. Network was constructed using human homologues of identified mouse proteins, where connections represent direct (solid lines) or indirect interactions (dashed lines).

WAT proteins of interest, including FABP4, PPAR $\gamma, \mathrm{C} / \mathrm{EBP} \alpha, \mathrm{C} / \mathrm{EBP} \beta$, and LPL. Four proteins (FABP4, PPAR $\gamma, \mathrm{C} / \mathrm{EBP} \alpha$, and C/EBP $\beta$ ) were markedly up-regulated in OP mice compared to OR and ND mice, whereas LPL levels were not altered upon HFD feeding (data not shown) or TH treatment (Fig. 5). Most proteins were also down-regulated in response to TH treatment in HFD-induced obese mice.

\section{Network analysis of proteomic data}

To further investigate the biological roles of molecules identified in this study, we performed network analysis using Ingenuity Pathway Analysis (IPA) based on the proteomic data. The representative network in WAT is shown in Fig. 6, and these genes were found to be associated with lipid metabolism, molecular transport, and small molecule biochemistry when ranked by $p$-value significance. IPA network analysis predicted possible interactions between Fabp4, Ppary, Anxa1, and Idh1. Unfortunately, PPAR $\gamma$ could not be detected using 2-DE, although it was activated by TH treatment in the network analysis.

Validation of results of IPA network analysis using real-time RT-PCR

To evaluate the results of the IPA network analysis, the predicted target genes (Anxa1, Fabp4, and Idh1) were further confirmed by determining their mRNA levels using real-time RT-PCR (Fig. 7). HFD treatment remarkably activated these predicted targets. Moreover, expression levels of these genes were markedly reduced by TH treatment.

\section{Discussion}

In the present study, we performed a comparative analysis of WAT protein expression profiles in HFD-induced obese mice treated with anti-obesity herbal medicine by 2-DE 


\section{Cellular Physiology Cell Physiol Biochem 2015;35:1482-1498 \begin{tabular}{ll|l} 
and BoI 10.1159/000373967 & $\begin{array}{l}\text { O 2015 S. Karger AG, Basel } \\
\text { www.karger.com/cpb }\end{array}$ \\
\cline { 2 - 3 }
\end{tabular} Kim et al.: Anti-Obesity Herbal Medicine Alters WAT Proteome}

Fig. 7. Validation of proteomic data and predicted targets generated by IPA analysis using real-time RT-PCR. mRNA expression patterns of three targets from WAT of experimental groups by real-time RTPCR analysis. Real-time PCR results are expressed as relative intensity normalized to Gusb gene expression and represent the mean \pm S.E.M of triplicate independent experiments. Statistical significance was determined by One-way ANOVA test, where $* * p<0.01$.

combined with MALDI-TOF-MS. Our results firmly establish that $\mathrm{TH}$, a traditional herbal medicine, significantly reduced body weight gain and significantly altered regulation of WAT proteins. From the current proteomic study, we identified a total of 57 proteins showing differential expression among the experimental groups, and some were previously unrecognized in the context of obesity. Among differentially regulated proteins between $\mathrm{OP}$ as well as OR and TH mice, a total of 12 proteins are discussed below due to space limitations.

Importantly, there were higher levels of Annexin A1 (ANXA1) and Annexin A5 (ANXA5) in OP mice, which may be associated with elevated lipid synthesis in

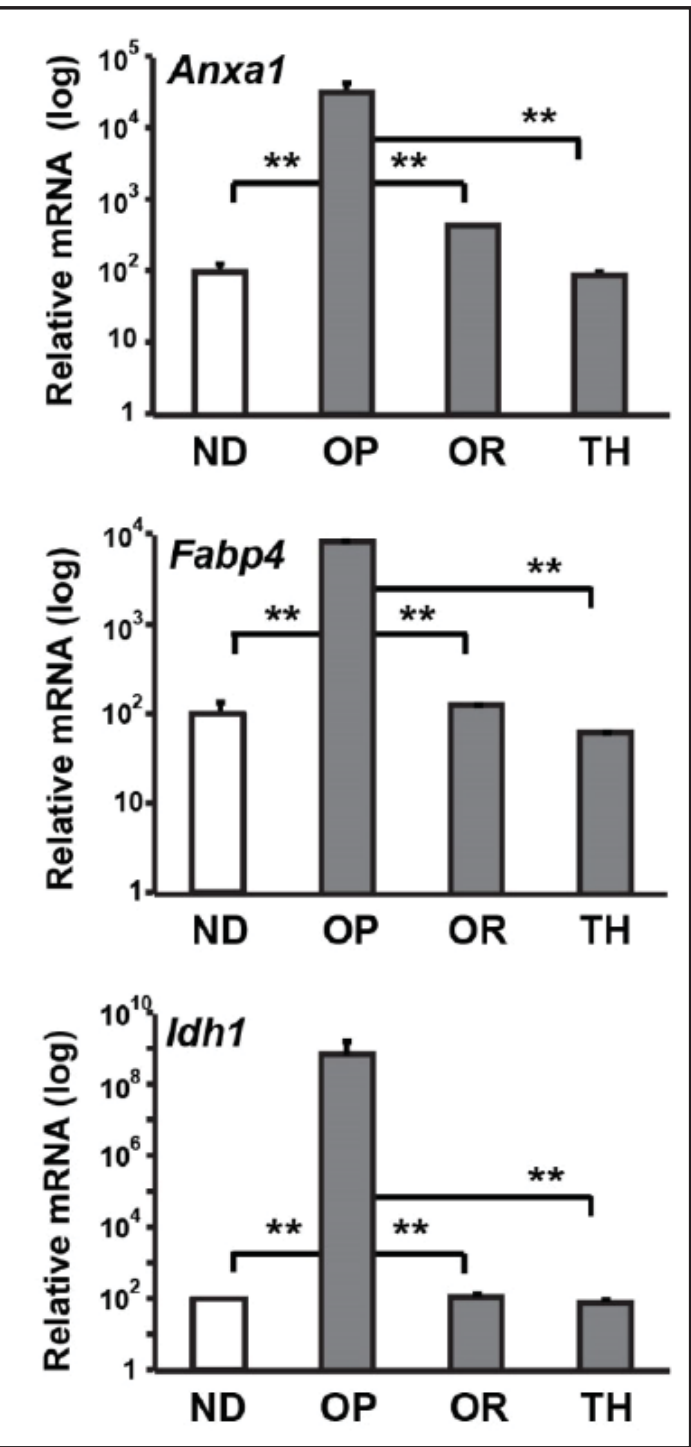
WAT. ANXA1 is a glucocorticoid-regulated protein that has been implicated in cell signaling and proliferation, and several isoforms of ANXA1 in 2-DE have been identified in adipose tissue of rodents [35]. Significant reduction of ANXA1 protein levels in both OR and TH mice may be due to decreased lipid formation. Similarly, ANXA5 was also up-regulated in OP mice but markedly down-regulated in OR and TH mice. ANXA5 is known to exhibit high affinity for anionic phospholipids in lipid membranes and protects the lipid membrane barrier against damage caused by inflammation [36]. Moreover, there is an association between inflammatory molecule levels and visceral obesity $[37,38]$. A recent study demonstrated that SNPs of ANXA5 are associated with susceptibility to being overweight or obese in Koreans [39]. Taken together, both ANXA1 and ANXA5 may play important roles in lipid metabolism and may be associated with obesity development in HFD-fed mice.

Cofilin-1 (CFL1) showed increased expression in WAT from obese mice along with reduced expression in OR and TH groups. CFL1 is a well known actin cytoskeleton-regulating protein [40]. There are limited reports concerning differential expression of CFL1 in the context of obesity. Recently, it was demonstrated that protein levels of CFL1 are increased during differentiation of 3T3-L1 preadipocytes due to PKA activity [41]. Although the physiological role of CFL1 in WAT has not yet been demonstrated, CFL1 overexpression is known to inhibit brown fat deposition as well as repress expression of browning marker genes such as UCP1, PRDM16, and PGC-1 $\alpha$ [42]. Therefore, altered protein expression of 


\section{Cellular Physiology Cell Physiol Biochem 2015;35:1482-1498 \begin{tabular}{ll|l} 
DOI: 10.1159/000373967 & $\begin{array}{l}\text { C 2015 S. Karger AG, Basel } \\
\text { www.karger.com/cpb }\end{array}$ \\
\hline
\end{tabular}}

Fig. 8. Summary on differentially regulated proteins/genes determining phenotypic differences between obesity susceptibility (OP) and resistance (OR) in mice fed HFD. Effects of anti-obesity herbal medicine are also described. ( $\uparrow$ ) Up-regulation, $(\downarrow)$ down-regulation. For abbreviated protein names, see Abbreviations.

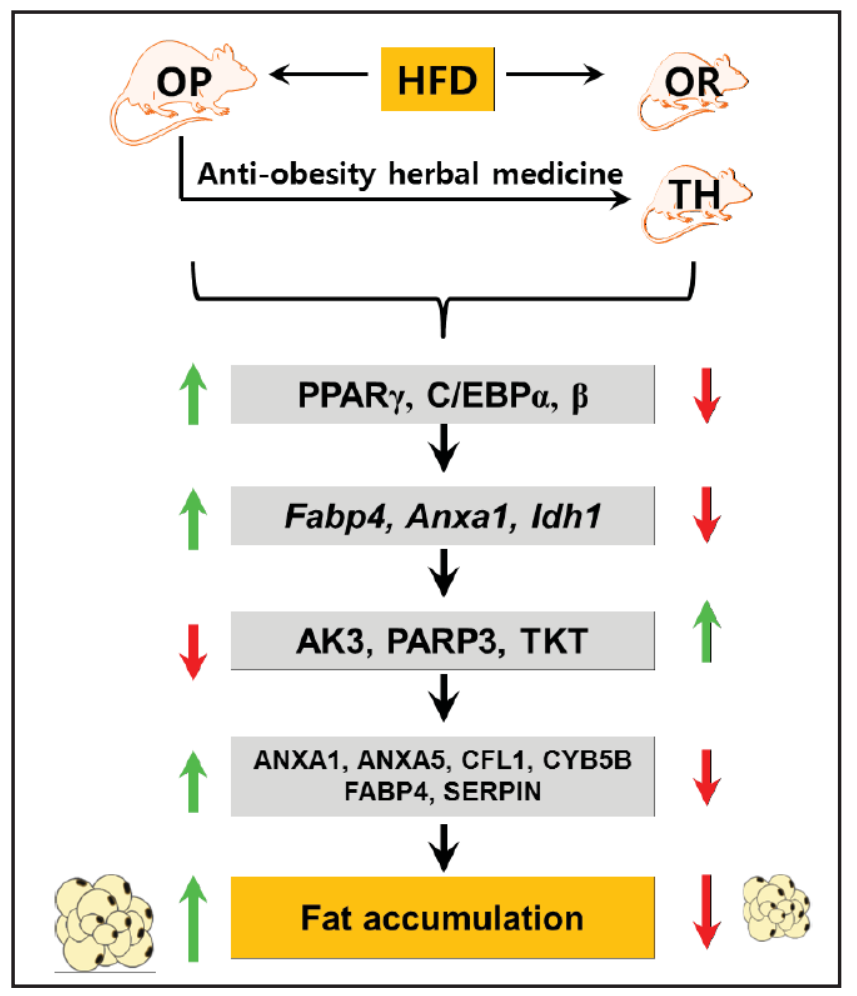

CFL1 in OR and TH mice is likely associated with possible browning characteristics of WAT, thereby affecting obesity resistance [43].

Elevated expression levels of cytochrome b5 type B (CYB5B) in obese mice also drew our attention. There are contradictory results concerning expression patterns of genes involved in mitochondrial oxidative metabolism in WAT from obese subjects. For instance, Marrades et al. [44] showed that orchestrated down-regulation of genes involved in oxidative metabolic pathways, including the cytochrome family, contributes to weight gain susceptibility in humans. In contrast, a recent study reported a 3.83-fold increase in cytochrome P450 expression in obese mice [45]. Our proteomic data also indicate increased protein expression of CYB5B in HFD-fed obese mice as well as reduced expression in OR and TH-treated mice. Taken together, other mechanisms seem to be responsible for these differences and thus further studies are required to clarify this issue.

As another interesting result, fatty acid binding protein 4 (FABP4) was highly expressed in OP mice. FABP4 is one of the most abundant proteins in mature adipocytes and is also detected at high concentrations in human serum. Although the biological role of FABP4 is not fully understood, it has been linked to insulin sensitivity, lipid metabolism, and inflammation [46]. Previously, we have shown that FABP4 levels are elevated in obese and diabetic individuals, and such increased levels are closely correlated with adverse lipid profiles, insulin resistance, and vascular smooth muscle cell proliferation [47-50]. In this study, protein and mRNA expression of FABP4 were reduced in OR and TH mice, which suggests alleviation of fat accumulation in adipocytes. In support of this, data from previous studies have shown that FABPs are involved in systemic regulation of lipid and glucose metabolism, and blood levels of FABP4 are positively associated with body weight and fat mass [51,52].

One of the most important findings in the current proteomic study was significant up-regulation of serine/cysteine peptidase inhibitor (SERPIN) in obese mice, whereas its expression was reduced in both OR and TH-treated mice. Data from our previous study showed that SERPIN expression is significantly higher in males than in females in both ND and HFD rats [26]. Other studies have also demonstrated that SERPINs could play an important role in obesity development $[53,54]$. For example, SERPIN family vaspin is highly 


\section{Cellular Physiology Cell Physiol Biochem 2015;35:1482-1498 \\ \begin{tabular}{l|l} 
and Biochemist $\begin{array}{l}\text { DOI: 10.1159/000373967 } \\
\text { Published online: March 12, } 2015\end{array}$ & $\begin{array}{l}\text { (c) 2015 S. Karger AG, Basel } \\
\text { www.karger.com/cpb }\end{array}$ \\
\cline { 2 - 3 } Kim &
\end{tabular}}

expressed in WAT from obese rats at the peak of obesity, and elevated blood vaspin levels are associated with obesity and insulin sensitivity [53]. However, long-term physical training combined with weight loss has been shown to increase blood vaspin levels, suggesting there is no clear link between vaspin and fat accumulation [53]. As OR mice showed decreased SERPIN levels in WAT, this protein may be associated with obesity resistance.

As another important finding, GTP:AMP phosphotransferase AK3 (AK3) and PARP3 showed lower expression levels in HFD-induced obese mice. One of the main functions of AK3 is to maintain homeostasis of cellular nucleotides by catalyzing the interconversion of nucleoside phosphates, and it is a central player in cellular energy metabolism [55]. PARP3 is a member of the PARP family catalyzing ADP ribosylation, which is a key post-translational modification step for proteins involved in various signaling pathways such as DNA damage and energy metabolism [56]. However, to date, no evidence has linked AK3 or PARP3 to lipid metabolism and obesity. Thus, higher expression of AK3 and PARP3 in response to TH treatment may regulate obesity by maintaining homeostasis of cellular nucleotides and energy metabolism. This is the first report demonstrating possible roles for AK3 and PARP3 in HFD-induced obesity.

Similarly, reduced protein expression of transketolase (TKT) was also observed in obese mice. Indeed, TKT is a ubiquitous protein used in multiple metabolic pathways, and disruption of a single TKT allele can slow growth of adipose tissue [57]. A previous study demonstrated that TKT-null mice display preferential reduction of adipose tissue, suggesting that obesity may be treated by inhibition of TKT in adipose tissue [57].

In this study, we also determined expression levels of key players during adipocyte differentiation such as peroxisome proliferator-activated receptor-gamma (PPAR $\gamma$ ) and CCAAT/enhancer binding proteins (C/EBPs) [58], which were not detected by our proteomic analysis. In addition to adipose tissue development, members of the C/EBP and PPAR family are involved in regulation of lipid metabolism [59-61]. C/EBP $\beta$ is the first transcription factor induced following exposure of preadipocytes to differentiation, and is thus postulated to be involved in directing the differentiation process. In accordance with this opinion, expression of $\mathrm{C} / \mathrm{EBP} \beta$ in preadipocytes accelerates the rate of C/EBP $\alpha$ induction and adipogenesis in response to hormonal inducers, indicating its stimulatory factor in adipogenesis [62]. Interestingly, protein levels of PPAR $\gamma$ and C/EBPs were reduced in OR and TH groups, suggesting that $\mathrm{TH}$ played a crucial role in alleviating adiposity in HFD-fed obese mice. Similarly, numerous natural compounds such as catethins, capsaicin, and berberine have been shown to act as inhibitors of adipogenesis by reducing expression of adipogenic factors [63-65].

IPA network analysis predicted interactions between Fabp4, Ppary, Anxa1, and Idh1. One important network was identified involving Fabp4. However, the mechanisms by which FABP4 promote insulin resistance and inflammation are not fully understood. Ppary has been reported to be a potent modulator of adipogenesis, acting as a transcription factor of Fabp4 expressed in mature adipocytes [66]. A recent study found that FABP4 is up-regulated while PPAR $\gamma$ is down-regulated in human visceral fat and mouse epididymal fat compared to subcutaneous fat [49]. Furthermore, suppression of PPAR $\gamma$ by FABP4 in visceral fat may explain the reported role of FABP4 in the development of obesity-related morbidities such as insulin resistance and diabetes.

In addition to our proteomic data, we observed elevated expression of Idh1 encoding isocitrate dehydrogenase (IDH) in HFD-induced obese mice. Elevated transcription and protein expression of Idh1 can increase cellular levels of NADPH, which causes lipid deposition in adipocytes as well as obesity and fatty liver [67]. Reduction of cellular NADPH levels resulting from suppression of Idh1 expression in OR and TH mice was associated with less lipid deposition in adipocytes. Therefore, by taking advantage of the suppressive or inhibitory effects of IDH inhibitors, pharmaceutically effective materials for the treatment of obesity, hyperlipidemia, and fatty liver can be developed [68].

In conclusion, the current study demonstrated that $\mathrm{TH}$, a traditional herbal medicine, shows promising anti-obesity effects through alteration of WAT protein expression in HFD- 


\section{Cellular Physiology Cell Physiol Biochem 2015;35:1482-1498 \begin{tabular}{l|l} 
DOI: 10.1159/000373967 & O 2015 S. Karger AG, Basel
\end{tabular} and Biochemistry Published online: March 12, 2015 www.karger.com/cpb \\ Kim et al.: Anti-Obesity Herbal Medicine Alters WAT Proteome}

fed obese mice. Further, several of the identified proteins are recognized for the first time in the context of obesity. Multi-components from TH might regulate numerous genes/proteins involved in adipogenesis and lipid metabolism, which was further confirmed by IPA network analysis. This study is the first to link TH, a natural anti-obesity medicine, to its regulatory actions (Fig. 8). However, more research should be carried out to further unravel the cellular pathways behind the multi-components of $\mathrm{TH}$.

\section{Abbreviations}

2-DE (two-dimensional electrophoresis); AK3 (GTP:AMP phosphotransferase AK3 mitochondrial); ANXA1/Anxa1 (annexin A1); ANXA5 (annexin A5); C/EBP (CCAAT/ enhancer binding protein); CFL1 (cofilin 1); CYB5b (cytochrome b5); FABP4/Fabp4 (fatty acid binding protein 4); Gusb (glucuronidase beta); HFD (high fat diet); IDH1/Idh1 (isocitrate dehydrogenase 1); LPL (lipoprotein lipase); OP (obesity-prone); OR (obesity-resistant); PARP3 (poly (ADP-ribose) polymerase 3); PPAR $\gamma$ (peroxisome proliferator-activated receptor $\gamma$ ); SERPIN (serine/cysteine peptidase inhibitor); TKT (transketolase).

\section{Acknowledgements}

This work was supported by the Bio-Synergy Research Project (NRF2012M3A9C4048818) and the Mid-career Researcher Program (2013R1A2A2A05004195) through an NRF grant funded by the Ministry of Science, ICT and Future Planning, Korea.

\section{Disclosure Statement}

The authors have declared no conflict of interest.

\section{References}

1 Haslam DW, James WP: Obesity. Lancet 2005;366:1197-1209.

2 Van Gaal LF, Maggioni AP: Overweight, obesity, and outcomes: Fat mass and beyond. Lancet 2014;383:935936.

3 Yusuf S, Hawken S, Ounpuu S, Bautista L, Franzosi MG, Commerford P, Lang CC, Rumboldt Z, Onen CL, Lisheng L, Tanomsup S, Wangai P, Jr., Razak F, Sharma AM, Anand SS: Obesity and the risk of myocardial infarction in 27,000 participants from 52 countries: A case-control study. Lancet 2005;366:1640-1649.

4 Gaur A, Pal GKMM, Ananthanarayanan PH, Pal P: Role of ventromedial hypothalamus in high fat diet induced obesity in male rats: Association with lipid profile, thyroid profile and insulin resistance. Ann Neurosci 2014;21:104-107.

5 Bartness TJ, Polk DR, McGriff WR, Youngstrom TG, DiGirolamo M: Reversal of high-fat diet-induced obesity in female rats. Am J Physiol 1992;263:R790-797.

6 Sato M, Kawakami T, Kondoh M, Takiguchi M, Kadota Y, Himeno S, Suzuki S: Development of high-fat-dietinduced obesity in female metallothionein-null mice. FASEB J 2010;24:2375-2384.

7 Levin BE, Dunn-Meynell AA, Balkan B, Keesey RE: Selective breeding for diet-induced obesity and resistance in sprague-dawley rats. Am J Physiol 1997;273:R725-730.

8 Ji H, Outterbridge LV, Friedman MI: Phenotype-based treatment of dietary obesity: Differential effects of fenofibrate in obesity-prone and obesity-resistant rats. Metabolism 2005;54:421-429.

9 Nahas R: Complementary and alternative medicine approaches to blood pressure reduction: An evidencebased review. Can Fam Physician 2008;54:1529-1533. 


\section{Cellular Physiology Cell Physiol Biochem 2015;35:1482-1498 \begin{tabular}{l|l} 
and Biochemistry Published online: March 12, 2015 & $\begin{array}{l}\text { D 2015 S. Karger AG, Basel } \\
\text { www.karger.com/cpb }\end{array}$ \\
\hline
\end{tabular} \\ Kim et al.: Anti-Obesity Herbal Medicine Alters WAT Proteome}

10 Bell RA, Suerken CK, Grzywacz JG, Lang W, Quandt SA, Arcury TA: CAM use among older adults age 65 or older with hypertension in the united states: General use and disease treatment. J Altern Complement Med 2006;12:903-909.

11 Wang J, Feng B, Xiong X: Chinese herbal medicine for the treatment of obesity-related hypertension. Evid Based Complement Alternat Med 2013;2013:757540.

12 Lenon GB, Li KX, Chang YH, Yang AW, Da Costa C, Li CG, Cohen M, Mann N, Xue CC: Efficacy and safety of a chinese herbal medicine formula ( $\mathrm{rcm}-104)$ in the management of simple obesity: A randomized, placebocontrolled clinical trial. Evid Based Complement Alternat Med 2012;2012:435702.

13 Kwak DH, Lee JH, Kim T, Ahn HS, Cho WK, Ha H, Hwang YH, Ma JY: Aristolochia manshuriensis kom inhibits adipocyte differentiation by regulation of ERK1/2 and AKT pathway. PLoS One 2012;7:e49530.

14 Jeong S, Chae K, Jung YS, Rho YH, Lee J, Ha J, Yoon KH, Kim GC, Oh KS, Shin SS, Yoon M: The korean traditional medicine gyeongshingangjeehwan inhibits obesity through the regulation of leptin and PPARalpha action in OLETF rats. J Ethnopharmacol 2008;119:245-251.

15 Hasani-Ranjbar S, Jouyandeh Z, Abdollahi M: A systematic review of anti-obesity medicinal plants - an update. J Diabetes Metab Disord 2013;12:28.

16 Yun JW: Possible anti-obesity therapeutics from nature--a review. Phytochemistry 2010;71:1625-1641.

17 Atta Ur R, Zaman K: Medicinal plants with hypoglycemic activity. J Ethnopharmacol 1989;26:1-55.

18 Park S, Park JS, Cheon C, Yang YJ, An C, Jang BH, Song YK, Go H, Lee JA, Shin Y, Ko SG: A pilot study to evaluate the effect of taeumjowi-tang on obesity in korean adults: Study protocol for a randomised, doubleblind, placebo-controlled, multicentre trial. Trials 2012;13:33.

19 Park S, Nahmkoong W, Cheon C, Park JS, Jang BH, Shin Y, Kim KS, Go H, Song YK, Ko SG: Efficacy and safety of taeeumjowi-tang in obese korean adults: A double-blind, randomized, and placebo-controlled pilot trial. Evid Based Complement Alternat Med 2013;2013:498935.

20 Hwang MJ, Shin HD, Song MY: Review of literature on herbal medicines for the treatment of obesity in Korea: mainly papers since 2000. J Oriental Rehab Med 2006;16:65-81.

21 Park S, Nahmkoong W, Cheon C, Park JS, Jang BH, Shin Y, Kim KS, Go H, Song YK, Ko SG: Efficacy and safety of taeeumjowi-tang in obese Korean adults; a double-blind, randomized, and placebo-controlled pilot trial. Evid Based Complement Alternat Med 2013;2013:498935.

22 Park S, Ahn IS, Kim DS, Kang S, Kwon DY, Yang J: Anti-obesity effects of tae-um-jo-wee-tang and do-damtang in female rats with diet-induced obesity. J Appl Biol Chem 2010;53:44-50.

23 Kim KS, Lee DU, KimYL, Hwang MJ, Kim GW, Koo BS: Anti-obesity and anti-hyperlipidemic effects of Taeyeumjowee-tang and its modified prescription. J Orient Neuropsychiatry 2007;18:57-74.

24 Zolg JW, Langen H: How industry is approaching the search for new diagnostic markers and biomarkers. Mol Cell Proteomics 2004;3:345-354.

25 Honore B, Ostergaard M, Vorum H: Functional genomics studied by proteomics. Bioessays 2004;26:901915.

26 Mukherjee R, Choi JW, Choi DK, Oh TS, Liu H, Yun JW: Gender-dependent protein expression in white adipose tissues of lean and obese rats fed a high fat diet. Cell Physiol Biochem 2012;29:617-634.

27 Choi DK, Oh TS, Choi JW, Mukherjee R, Wang X, Liu H, Yun JW: Gender difference in proteome of brown adipose tissues between male and female rats exposed to a high fat diet. Cell Physiol Biochem 2011;28:933-948.

28 Joo JI, Yun JW: Gene expression profiling of adipose tissues in obesity susceptible and resistant rats under a high fat diet. Cell Physiol Biochem 2011;27:327-340.

29 Viguerie N, Poitou C, Cancello R, Stich V, Clement K, Langin D: Transcriptomics applied to obesity and caloric restriction. Biochimie 2005;87:117-123.

30 Higami Y, Pugh TD, Page GP, Allison DB, Prolla TA, Weindruch R: Adipose tissue energy metabolism: Altered gene expression profile of mice subjected to long-term caloric restriction. FASEB J 2004;18:415-417.

31 Futcher B, Latter GI, Monardo P, McLaughlin CS, Garrels JI: A sampling of the yeast proteome. Mol Cell Biol 1999;19:7357-7368.

32 Gygi SP, Rochon Y, Franza BR, Aebersold R: Correlation between protein and mRNA abundance in yeast. Mol Cell Biol 1999;19:1720-1730.

33 Richards J, Le Naour F, Hanash S, Beretta L: Integrated genomic and proteomic analysis of signaling pathways in dendritic cell differentiation and maturation. Ann N Y Acad Sci 2002;975:91-100. 


\section{Cellular Physiology Cell Physiol Biochem 2015;35:1482-1498

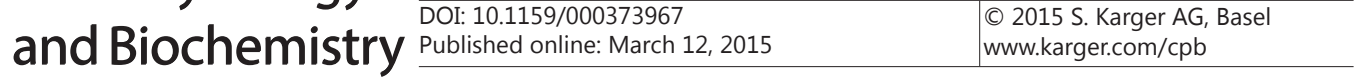 \\ Kim et al.: Anti-Obesity Herbal Medicine Alters WAT Proteome}

34 Joo JI, Oh TS, Kim DH, Choi DK, Wang X, Choi JW, Yun JW: Differential expression of adipose tissue proteins between obesity-susceptible and -resistant rats fed a high-fat diet. Proteomics 2011;11:1429-1448.

35 Lanne B, Dahllof B, Lindahl C, Ebefors K, Kanmert I, von Bahr H, Miliotis T, Nystrom AC, Arnerup G, Paulsons I, Kerb S, Oakes N: PPARalpha and PPARgamma regulation of liver and adipose proteins in obese and dyslipidemic rodents. J Proteome Res 2006;5:1850-1859.

36 Willems GM, Janssen MP, Comfurius P, Galli M, Zwaal RF, Bevers EM: Competition of annexin v and anticardiolipin antibodies for binding to phosphatidylserine containing membranes. Biochemistry 2000;39:1982-1989.

37 Creutz CE, Hira JK, Gee VE, Eaton JM: Protection of the membrane permeability barrier by annexins. Biochemistry 2012;51:9966-9983.

38 Tchernof A, Despres JP: Pathophysiology of human visceral obesity: An update. Physiol Rev 2013;93:359404.

39 Seok H, Park HJ, Lee BW, Kim JW, Jung M, Lee SR, Park KH, Park YG, Baik HH, Chung JH: Association of annexin a5 polymorphisms with obesity. Biomed Rep 2013;1:654-658.

40 Munsie LN, Desmond CR, Truant R: Cofilin nuclear-cytoplasmic shuttling affects cofilin-actin rod formation during stress. J Cell Sci 2012;125:3977-3988.

41 Borkowski K, Wrzesinski K, Rogowska-Wrzesinska A, Audouze K, Bakke J, Petersen RK, Haj FG, Madsen L, Kristiansen K: Proteomic analysis of cAMP-mediated signaling during differentiation of 3T3-L1 preadipocytes. Biochim Biophys Acta 2014;1844:2096-2107.

42 Kamal AH, Kim WK, Cho K, Park A, Min JK, Han BS, Park SG, Lee SC, Bae KH: Investigation of adipocyte proteome during the differentiation of brown preadipocytes. J Proteomics 2013;94:327-336.

43 Hsieh CH, Chen GC, Chen PH, Wu TF, Chao PM: Altered white adipose tissue protein profile in C57BL/6J mice displaying delipidative, inflammatory, and browning characteristics after bitter melon seed oil treatment. PLoS One 2013;8:e72917.

44 Marrades MP, Gonzalez-Muniesa P, Arteta D, Martinez JA, Moreno-Aliaga MJ: Orchestrated downregulation of genes involved in oxidative metabolic pathways in obese vs. Lean high-fat young male consumers. J Physiol Biochem 2011;67:15-26.

45 Merkestein M, McTaggart JS, Lee S, Kramer HB, McMurray F, Lafond M, Boutens L, Cox R, Ashcroft FM: Changes in gene expression associated with FTO overexpression in mice. PLoS One 2014;9:e97162.

46 Queipo-Ortuno MI, Escote X, Ceperuelo-Mallafre V, Garrido-Sanchez L, Miranda M, Clemente-Postigo M, Perez-Perez R, Peral B, Cardona F, Fernandez-Real JM, Tinahones FJ, Vendrell J: Fabp4 dynamics in obesity: Discrepancies in adipose tissue and liver expression regarding circulating plasma levels. PLoS One 2012; 7:e48605.

47 Girona J, Rosales R, Plana N, Saavedra P, Masana L, Vallve JC: Fabp4 induces vascular smooth muscle cell proliferation and migration through a MAPK-dependent pathway. PLoS One 2013;8:e81914.

48 Aragones G, Saavedra P, Heras M, Cabre A, Girona J, Masana L: Fatty acid-binding protein 4 impairs the insulin-dependent nitric oxide pathway in vascular endothelial cells. Cardiovasc Diabetol 2012;11:72.

49 Garin-Shkolnik T, Rudich A, Hotamisligil GS, Rubinstein M: Fabp4 attenuates PPARgamma and adipogenesis and is inversely correlated with PPARgamma in adipose tissues. Diabetes 2014;63:900-911.

50 Cabre A, Lazaro I, Cofan M, Jarauta E, Plana N, Garcia-Otin AL, Ascaso JF, Ferre R, Civeira F, Ros E, Masana L: Fabp4 plasma levels are increased in familial combined hyperlipidemia. J Lipid Res 2010;51:1173-1178.

51 Xu A, Wang Y, Xu JY, Stejskal D, Tam S, Zhang J, Wat NM, Wong WK, Lam KS: Adipocyte fatty acid-binding protein is a plasma biomarker closely associated with obesity and metabolic syndrome. Clin Chem 2006;52:405-413.

52 Engl J, Ciardi C, Tatarczyk T, Kaser S, Laimer M, Laimer E, Weiss H, Aigner F, Molnar C, Tilg H, Patsch JR, Ebenbichler CF: A-FABP--a biomarker associated with the metabolic syndrome and/or an indicator of weight change? Obesity (Silver Spring) 2008;16:1838-1842.

53 Li Q, Chen R, Moriya J, Yamakawa J, Sumino H, Kanda T, Takahashi T: A novel adipocytokine, visceral adipose tissue-derived serine protease inhibitor (vaspin), and obesity. J Int Med Res 2008;36:625-629.

54 Youn BS, Kloting N, Kratzsch J, Lee N, Park JW, Song ES, Ruschke K, Oberbach A, Fasshauer M, Stumvoll M, Bluher M: Serum vaspin concentrations in human obesity and type 2 diabetes. Diabetes 2008;57:372-377.

55 Ulschmid JK, Rahlfs S, Schirmer RH, Becker K: Adenylate kinase and GTP:AMP phosphotransferase of the malarial parasite plasmodium falciparum. Central players in cellular energy metabolism. Mol Biochem Parasitol 2004;136:211-220. 


\section{Cellular Physiology Cell Physiol Biochem 2015;35:1482-1498 \begin{tabular}{l|l} 
DOI: 10.1159/000373967 & O 2015 S. Karger AG, Basel
\end{tabular} and Biochemistry Published online: March 12, 2015 www.karger.com/cpb}

Kim et al.: Anti-Obesity Herbal Medicine Alters WAT Proteome

56 Boehler C, Gauthier LR, Mortusewicz O, Biard DS, Saliou JM, Bresson A, Sanglier-Cianferani S, Smith S, Schreiber V, Boussin F, Dantzer F: Poly(adp-ribose) polymerase 3 (parp3), a newcomer in cellular response to DNA damage and mitotic progression. Proc Natl Acad Sci U S A 2011;108:2783-2788.

57 Xu ZP, Wawrousek EF, Piatigorsky J: Transketolase haploinsufficiency reduces adipose tissue and female fertility in mice. Mol Cell Biol 2002;22:6142-6147.

58 Gregoire FM, Smas CM, Sul HS: Understanding adipocyte differentiation. Physiol Rev 1998;78:783-809.

59 Darlington GJ, Ross SE, MacDougald OA: The role of C/EBP genes in adipocyte differentiation. J Biol Chem 1998;273:30057-30060.

60 Evans RM, Barish GD, Wang YX: PPARs and the complex journey to obesity. Nat Med 2004;10:355-361.

61 Millward CA, Heaney JD, Sinasac DS, Chu EC, Bederman IR, Gilge DA, Previs SF, Croniger CM: Mice with a deletion in the gene for CCAAT/enhancer-binding protein beta are protected against diet-induced obesity. Diabetes 2007;56:161-167.

62 Yeh WC, Cao Z, Classon M, McKnight SL: Cascade regulation of terminal adipocyte differentiation by three members of the C/EBP family of leucine zipper proteins. Genes Dev 1995;9:168-181.

63 Harmon AW, Harp JB: Differential effects of flavonoids on 3T3-L1 adipogenesis and lipolysis. Am J Physiol Cell Physiol 2001;280:C807-813.

64 Hsu CL, Yen GC: Effects of capsaicin on induction of apoptosis and inhibition of adipogenesis in 3T3-L1 cells. J Agric Food Chem 2007;55:1730-1736.

65 Huang C, Zhang Y, Gong Z, Sheng X, Li Z, Zhang W, Qin Y: Berberine inhibits 3T3-L1 adipocyte differentiation through the PPARgamma pathway. Biochem Biophys Res Commun 2006;348:571-578.

66 Tontonoz P, Spiegelman BM: Fat and beyond: The diverse biology of PPARgamma. Annu Rev Biochem 2008;77:289-312.

67 Koh HJ, Lee SM, Son BG, Lee SH, Ryoo ZY, Chang KT, Park JW, Park DC, Song BJ, Veech RL, Song H, Huh TL: Cytosolic NADP+-dependent isocitrate dehydrogenase plays a key role in lipid metabolism. J Biol Chem 2004;279:39968-39974.

68 Shin CY, Jung MY, Lee IK, Son M, Kim DS, Lim JI, Kim SH, Yoo M, Huh TL, Sohn YT, Kim WB: Anti-diabetic effects of DA-11004, a synthetic idpc inhibitor in high fat high sucrose diet-fed C57BL/6J mice. Arch Pharm Res 2004;27:48-52. 